\title{
INVESTIGATION OF ANTI-INFLAMMATORY EFFECT OF LIQUID EXTRACTS FROM CAPSICUM ANNUUM L. IN SPECIFIC AND NONSPECIFIC ADJUVANT- INDUCED ARTHRITIS
}

\author{
Yanina V. Boshkova, Yurii A. Boiko \\ Odessa National Medical University, Ukraine
}

Background. The fruits of Capsicum annuum L. contain a significant amount of capsaicinoids and carotenoids. Thus, it seems interesting to investigate the therapeutic possibilities of using extracts from Capsicum annuum L. for the experimental treatment of adjuvant-induced arthritis.

Metods. As a vegetable raw material, the ripe fruits Capsicum annuum L. of the variety "Ukrainian bitter" were used. Extracts were obtained by alcohol maceration. For the study, young male rats from the Wistar line were used. To induce inflammatory arthritis, $0.1 \mathrm{ml}$ of Freund's complete adjuvant was administered to every animal through subplantar injection. The treatment was performed by daily application of liquid extracts (capsaicin concentration $0.42 \%$ ) to the adjuvant administration area. For a positive control, a group of animals was used, who were treated with ointment containing ibuprofen (50 mg / $1 \mathrm{~g}$ of ointment). A group of animals did not received any negative control. To characterize the therapeutic effectiveness of the treatment used, the dynamics of the following indices was determined: thickness of the nonspecific and specific inflammatory edema, changes in the leukocyte composition of the blood.

Results. Treatment with liquid extracts from Capsicum annuum L. allowed to reduce the thickness of the edema on the 9th day of treatment (comparison with the negative control) and 12 (comparison with the positive control). Until the 28th day of treatment, the size of the inflammatory edema in the animals of the experimental group had been 20-25\% less than in animals with positive and negative controls. Preliminary treatment with liquid extracts also prevented the development of autoimmune inflammation of the contralateral limb, which was observed in the control groups (an increase in the metatarsal joint by 12-15\%). The total number of leukocytes (1.3 times less than in the negative control, 1.1 times less than in the positive control, on day 28 of treatment) and shifts in the leukocyte formula in the animals of the experimental group were less pronounced than in control groups' animals.

Conclusion. Thus, we can draw a conclusion about the effectiveness of liquid extracts from Capsicum annuum L. in a chronic inflammatory process. 